\title{
Doenças sexualmente transmissíveis: conceitos, atitudes e percepções en- tre coletores de lixo
}

\section{Sexually transmitted diseases: concepts, attitudes and perceptions of dustmen}

\author{
Elucir Gir*, Tokico Murakawa Moriya*, Maria Lúcia do Carmo Cruz Robazzi**, Maria Helena Pessini de \\ Oliveira ** Sônia Maria Vilella Bueno***, Alcyone Artioli Machado***
}

\begin{abstract}
GIR, E. et al. Doenças sexualmente transmissíveis: conceitos, atitudes e percepções entre coletores de lixo. Rev. Saúde públ., S. Paulo, 25: 226-9, 1991. Apresentam-se os conceitos sobre DST entre $41(63,07 \%$ ) coletores de lixo de uma cidade do interior de São Paulo, com a finalidade de oferecer subsídios para a elaboração de programas de educação em saúde sobre DST, para este grupo da população e outros similares. Da análise dos dados coletados, em entrevista com os indivíduos, obteve-se que um número apreciável destes trabalhadores possuem conceitos inadequados sobre as DST. Estes resultados vêm denotar a desinformação e ausência de conhecimento existente sobre o assunto, requerendo portanto a implementação de ações educativas.
\end{abstract}

Descritores: Doenças sexualmente transmissíveis. Conhecimentos, atitudes e prática. Trabalhadores.

\section{Introdução}

Desde tempos remotos, as doenças sexualmente transmissiveis (DST) vêm acometendo a população, sendo que, ainda hoje, apesar de todo o avanço tecnológico e científico, estima-se elevada prevalência entre indivíduos de ambos os sexos, de diferentes classes sócio-econômicoculturais e com diversas práticas sexuais. Numerosos fatores determinam tal situação, dentre eles a rotatividade desregrada de parceiros e a falta de orientação adequada para as pessoas trabalharem essas questões, em relação a si e aos outros.

Ainda que não bastasse a morbidade das DST, já conhecida em nível de saúde pública, surge a AIDS, que, além da morbidez, acaba levando o indivíduo acometido, à morte.

No Brasil inexistem dados estatísticos preci-

* Departamento de Enfermagem Geral e Especializada da Escola de Enfermagem de Ribeirão Preto da Universidade de São Paulo (USP) - Ribeirão Preto, SP Brasil.

* Departamento de Enfermagem Materno-Infantil da Escola de Enfermagem de Ribeirão Preto da USP . Ribeirão Preto, SP - Brasil.

*** Departamento de Enfermagem Psiquiátrica e Ciências Humanas da Escola de Enfermagem de Ribeirão Preto da USP - Ribeirão Preto, SP - Brasil.

**** Departamento de Clínica Médica da Faculdade de Medicina de Ribeirão Preto da USP - Ribeirão Preto, SP - Brasil.

Separatas/Reprints: E. Gir - Av. Bandeirantes, 3900 - 14049 - Ribeirão Preto, SP - Brasil.

Publicação financiada pela FAPESP. Processo Medicina 90/4602-1. sos que revelem a sua real magnitude, uma vez que os dados disponíveis são de estudos isolados e das doenças de transmissão sexual, apenas a sífilis congênita e a AIDS, são de notificação compulsória. Segundo informações do Ministério da Saúde ${ }^{2,3}$, no período de 1979 a 1986 foram registrados 779 casos de sífilis congênita; quanto à AIDS tem-se o registro de 12.405 casos notificados de 1980 a 1990.

E, por esta razão, Antal $^{1}$ (1989) refere ser possível até ocorrer uma inversão na tendência crescente de algumas DST, em vista do aparecimento da AIDS, que com seu potencial letal vem provocando mudanças no comportamento sexual das pessoas. Contudo, as maiores preocupações não são apenas as altas prevalências das DST. As consequiências refletidas na saúde materno-infantil que recaem, também, nos aspectos sócio-econômicos, por si só, são suficientes para que estas doenças sejam destacadas como um dos grandes problemas de saúde no Brasil.

Portanto, planejou-se estudar uma população de nível sócio-econômico baixo para sondar qual a percepção que esta tem sobre o significado semântico de DST. Escolheu-se uma população de trabalhadores que executam atividades braçais e de menor condição social, os coletores de lixo*.

\footnotetext{
* Entende-se por coletor de lixo aquele indivíduo que executa o seu trabalho em caminhão receptor de lixo (excluindo-se os motoristas) e recolhe os resíduos urbanos em turnos alternados, com carga horária de trabalho aproximada de 8 horas por dia. São considerados sinônimos os termos garis e lixeiros.
} 
Robazzi $^{7}$ (1984) constatou que os coletores de lixo são pessoas desinformadas em relação a vários aspectos gerais, incluindo seus vários direitos adquiridos por lei, enquanto trabalhadores, e a aspectos específicos como, por exemplo, a utilização de equipamentos de proteção individual. Além disso, possuem hábitos indesejáveis, como os de fumar e ingerir bebidas alcoólicas, inclusive durante o trabalho, além de não terem qualificação profissional de acordo com os vários critérios recomendados, pois são recrutados ao serviço e, inclusive, não são submetidos a exames pré-admissionais ou periódicos, o que deveria acontecer pela insalubridade do trabalho que executam.

Diante desse quadro, os autores desse estudo, a maioria envolvida em programas educativos sobre DST/AIDS para a população em geral, propuseram-se a estudar os conceitos, as atitudes e as percepções que os coletores de lixo de uma cidade do interior de São Paulo têm a cerca dessas doenças, com a finalidade de, posteriormente, elaborar programas de educação em saúde sobre DST para este grupo da população, bem como a outras categorias de trabalhadores similares.

\section{Material e Método}

Os dados foram coletados através de entrevista com coletores de lixo lotados no Departamento de Urbanismo e Saneamento da Prefeitura Municipal, da cidade de Ribeirão Preto - SP, em 1986. Participaram do estudo $41(63,07 \%)$ de um total de $65(100 \%)$ lixeiros.

Como instrumento, elaborou-se formulário que serviu como roteiro da entrevista e registro das respostas. Este foi previamente submetido ao julgamento de três juízes e, após ajustes sugeridos, estabeleceu-se data e horário para a realização das entrevistas, de tal forma a não prejudicar o andamento do serviço e nem o horário de saída desses trabalhadores. Foram incluídos todos os sujeitos que estavam presentes na data estabelecida para a entrevista, que concordaram em participar da mesma e apresentavam-se em condições de serem a ela submetidos.

\section{Resultados}

Na Tabela 1 encontra-se a distribuição dos coletores de lixo, todos do sexo masculino, segundo idade e estado civil.

A maioria, ou seja, $80 \%$ (33) dos trabalhadores situou-se na faixa etária de 21 a 40 anos, dado justificável devido ao tipo de serviço execu-
Tabela 1. Distribuição segundo idade e estado civil dos coletores de lixo de Ribeirão Preto - SP, 1986.

\begin{tabular}{|c|c|c|c|c|}
\hline \multirow[b]{2}{*}{ Idade } & \multicolumn{3}{|c|}{ Estado Civil } & \multirow[b]{2}{*}{ Total } \\
\hline & Solteiro & Casado & Outros* & \\
\hline & N! & N? & N: & N: $f(\%)$ \\
\hline $11 \longmapsto 20$ & $\begin{array}{l}1 \\
9\end{array}$ & 0 & $\begin{array}{l}0 \\
4\end{array}$ & $\begin{array}{c}1(2,43) \\
2 ?(53,65)\end{array}$ \\
\hline $31 \mapsto 40$ & $\begin{array}{l}9 \\
0\end{array}$ & $\begin{array}{c}9 \\
10\end{array}$ & $\begin{array}{l}4 \\
1\end{array}$ & $\begin{array}{l}22(30,05) \\
11(26,82)\end{array}$ \\
\hline $41 \longmapsto 50$ & 1 & 2 & 2 & $5(12,19)$ \\
\hline $51 \longmapsto 60$ & 0 & 2 & 0 & $2(4,87)$ \\
\hline Total & 11 & 23 & 7 & $41(100)$ \\
\hline
\end{tabular}

"Outros = Desquitado, Amasiado, Separado.

tado, onde o esforço físico é um requisito a ser considerado.

Quanto ao nível de escolaridade, $7(17,07 \%)$ são analfabetos, $27(65,85 \%)$ com escolaridade até a quarta série, $6(14,63 \%)$ até a sexta ou sétima série e apenas $1(2,43 \%)$ com primeiro colegial.

Com referência à questão " $\mathrm{O}$ que é doença venérea (DV) ou doença sexualmente transmissível (DST)', 23(56,09\%) afirmaram não saber o que é, e $18(43,90 \%)$ atribuíram conceitos variados, alguns corretos, outros incompletos e até mesmo incorretos. (Tabela 2).

Tabela 2. Distribuição das respostas obtidas na questão "o que é DV ou DST?" Coletores de lixo, Ribeirão Preto - SP, 1986.

\begin{tabular}{lr}
\hline Respostas & Número \\
\hline Não sabe & 23 \\
Doença de rua & 4 \\
Doença que vem do sangue & 2 \\
Doença que pega fazendo sexo na rua & 2 \\
Parte de sexo & 2 \\
Doença de "Mulher" e "Homem" & 1 \\
Doença que não tem cura & 1 \\
Doença que pega através de relação sexual & 1 \\
Doença sexual & 1 \\
Doença provocada por amor ou falta de higiene & 1 \\
"Doença perigosa" & 1 \\
Doença contraida quando mal tratada & 1 \\
Doença que pega na "Zona" ou de outras pessoas & 1 \\
Doença de dormir com mulher & 1 \\
Doença de por pé no chão frio & 1 \\
Doença que dá problema no canal da urina & 1 \\
\hline
\end{tabular}

Três lixeiros deram respostas que foram desmembradas, totalizando 44 respostas.

Os exemplos de DST, mencionados pelos coletores de lixo, foram agrupados conforme Tabela 3. Foram mantidos os termos na forma usada pelos entrevistados, agrupando-se os similares conforme a compreensão dos autores.

Apesar de 23 garis informarem não saber o que é DST, muitos deles fizeram citações de doenças, algumas corretas e outras incorretas. Dentre aqueles que referiram saber o que é DST, alguns citaram doenças que não se enquadram entre as DST. 
Tabela 3. Distribuição das respostas sobre os exemplos de DST dos coletores de lixo de Ribeirão Preto - SP, 1986

\begin{tabular}{|c|c|}
\hline Exemplos de DST & $N^{\circ}$ \\
\hline $\begin{array}{l}\text { "Guinorréia", "Esquentamento", Gonorréia } \\
\text { "Cancru", Cancro }\end{array}$ & $\begin{array}{l}27 \\
21\end{array}$ \\
\hline *Mula & 11 \\
\hline Crista de Galo, Galo, Cavalo de Crista & 9 \\
\hline Chato & 2 \\
\hline * *Tuberculose Galopante & 1 \\
\hline${ }^{\star}$ Diabetis & 1 \\
\hline *Câncer & 1 \\
\hline •Capim & 1 \\
\hline *Bronquite & 1 \\
\hline Nāo sabe & 14 \\
\hline
\end{tabular}

A maioria das doenças foi citada na forma conhecida popularmente, como por exemplo: mula (Cancro mole); esquentamento, gonorréia, guinorréia (Gonorréia); chato (Pediculosis $\mathrm{Pu}-$ bis); crista de galo, galo, cavalo de crita (Condiloma Acuminado); cancro, cancru (Sífilis). Apenas para a AIDS não foi referido nenhum termo correspondente ao utilizado na linguagem popular.

Os achados da presente investigação, no que se refere à inclusão de outras doenças que não as DST, bem como a terminologia popular utilizada, são semelhantes aos resultados obtidos por Moriya e col..$^{5}(1985)$ em seu levantamento sobre o que os jovens sabem sobre as DST.

Os autores do presente trabalho, pela sua experiência nesse campo, têm percebido que algumas pessoas, independente do seu nível sócioeconômico e cultural, desconhecem as DST mais comuns e, por outro lado, acreditam ser outras doenças, até mesmo as não infecciosas, como tais. A doença mais citada foi Gonorréia, significando que os entrevistados sabem que essa doença é uma DST, enquanto que a Sífilis foi citada por 21 dos garis, o que de certa forma mostrou que é também uma doença conhecida pela metade dos entrevistados. As outras doenças como, Condiloma Acuminado, Cancro Mole, AIDS e Chato são pouco conhecidas como sendo DST.

Quanto ao conceito sobre modo de transmissão (Tabela 4 ), pouco mais da metade $(66 \%)$ da amostra estudada sabe como se transmitem as DST, mas muitos daqueles lixeiros que citaram como sendo a relação sexual o seu modo de transmissão, também fizeram referências a outras formas não corretas. Um número razoável desses trabalhadores ainda desconhece o modo de transmissão ou apresenta conceito errôneo.
Tabela 4. Distribuição das respostas sobre a questão: "Como pega DV ou DST?" entre os coletores de lixo de Ribeirão Preto, SP, 1986.

\begin{tabular}{lrc}
\hline Respostas & No & $\%^{*}$ \\
\hline Năo Sabe & 11 & $(26,8)$ \\
Pela relação sexual & 27 & $(65,9)$ \\
Pela falta de higiene & 2 & $(4,9)$ \\
Pega de animal (Mula, Cão) & 2 & $(4,9)$ \\
Ao sentar em banco & 2 & $(4,9)$ \\
No banheiro & 4 & $(9,8)$ \\
No caminhão de Lixo & 2 & $(4,9)$ \\
Através do sangue & 1 & $(2,4)$ \\
Pôr o pé no chão frio & 1 & $(2,4)$ \\
Pelo tempolvento & 1 & $(2,4)$ \\
\hline
\end{tabular}

* Houve mais de uma resposta por alguns sujeitos. A percentagem foi calculada em horizontal pelo seu total de sujeitos (41)

* Relação sexual = transar com camisinha; freqüentando chacrinha e tendo relação com mulheres; fazer programas com mulher de rua; através de relação; através do sexo; transar com quem tem a doença.

Sobre as medidas que devem ser tomadas quando estiver com DST, muitos dos entrevistados desconhecem a importância do não relacionamento sexual enquanto estiverem com DST e participação ao seu parceiro, existindo ainda conceitos de que há necessidade de afastar-se do serviço e isolar-se das pessoas da família. (Tabela 5).

Tabela 5. Distribuição das respostas dos coletores de lixo sobre a questāo: "Quando alguém está com DV ou DST o que esta pessoa deve fazer?", Ribeirão Preto, SP, 1986.

\begin{tabular}{lr}
\hline Respostas & $\mathrm{N}^{\circ *}$ \\
\hline Procurar tratamento médico & 29 \\
Não procurar farmácia & 4 \\
Isolar-se das pessoas da família & 3 \\
Não manter relação sexual & 3 \\
Tratar-se & 3 \\
Nāo sabe & 3 \\
Comunicar parceiro & 2 \\
Afastar-se do serviço & 2 \\
Não transmitir a outras pessoas & 1 \\
\hline *Alguns sujeitos emitiram mais de uma resposta
\end{tabular}

*Alguns sujeitos emitiram mais de uma resposta

Quanto à pergunta se os entrevistados receberam alguma orientação sobre o que é DV ou DST, 15 referiram que sim e 26 não. Dos que mencionaram sim, nove informaram que esta orientação foi obtida através de palestra no próprio local de trabalho, outros destacaram que foram informados em hospital, escola, casa assistencial à comunidade. Mencionaram, ainda terem obtido informações através de pesquisa médica e comentários, como também citaram como fontes de informações o médico e os amigos. 


\section{Comentários}

Os resultados obtidos na presente investigação mostram que um número apreciável de coletores de lixo possuem conceitos inadequados sobre DST, o que denota a falta de informações dos sujeitos estudados quanto a etiologia, modo de transmissão, prevenção, controle e tratamento dessas doenças.

Conforme constataram Oliveira e col. ${ }^{6}$ (1987) em trabalho realizado no Município de Ribeirão Preto-SP, os portadores de DST conservam ainda, nos dias de hoje, preconceitos e sentimentos de subestimação quando vivem tal experiência, chegando a se perceberem marginalizados e menosprezados socialmente. $\mathrm{O}$ temor da divulgação do diagnóstico talvez seja a justificativa mais plausivel para que os doentes procurem pessoas não preparadas profissionalmente para tratá-los, como curandeiros, balconistas de farmácias, entre outros, pensando desta forma, estar mantendo íntegra a sua moral.

$\mathrm{Na}$ verdade, isto retrata a existência de desiformação que existe em nosso meio, sobre as DST, seus meios de prevenção, complicações advindas de tratamento ineficaz, ou retardado, e mesmo a falta de conhecimento relativo à ética profissional, valor esse que deveria estar presente nos serviços de saúde.

Consequientemente, observa-se um verdadeiro descrédito em relação a serviços públicos de atendimentos à saúde, somado a outros fatores como a espera em longas filas para o atendimento, a impessoalidade do relacionamenti profissional de saúde $x$ paciente, as dificuldades de agendamentos das consultas, e outros. Desta forma, modificar o descrédito em relação aos serviços públicos é trabalho complexo e árduo e muito mais do âmbito da política existente no setor de saúde.

Quanto à desinformação, acredita-se que uma das armas mais importantes seja o processo educacional, para se tentar reverter ou minimizar esse problema. Neste sentido concordase com Jones ${ }^{4}$ (1986) quando afirma que a educação é o fator essencial para ajudar a conscientizar as pessoas a procurarem tratamento adequado e informações sobre as doenças.

A realização de programas educativos para a comunidade em geral, torna-se essencial, inclusive pela veiculação desses programas nos meios de comunicação como televisão e rádio, além de campanhas em jornais. Antes, porém, é necessária uma análise prévia de cada população, principalmente sobre os conceitos, preconceitos e crenças do grupo sobre o assunto que se pretende informar/educar e assim reforçar os conceitos positivos e trabalhar com os errôneos e negativos para que estes sejam substituídos em favor da saúde.

É necessário, portanto, que ações educativas sejam dirigidas a esta categoria de trabalhador, quer sejam em forma de palestras, cursos ou orientações individuais e específicas, empregando-se terminologia, bem como recursos audio-visuais e folhetos informativos adequados ao nível de escolaridade dos sujeitos, visandose ao entendimento das mensagens emitidas e, conseqüentemente, um processo de comunicação o mais efetivo possível.

Estas ações devem ser planejadas e oferecidas periodicamente de acordo com a necessidade e, para tanto, devem ser avaliadas através da aplicação de pré e pós-testes por ocasião das palestras e cursos, bem como pela monitorização da ocorrênciaa dos casos de DST.

GIR, E. et al. [Sexually transmitted diseases: concepts, attitudes and perceptions of dustmen]. Rev. Saúde públ., S.Paulo, 25: 226-9, 1991. The concepts regarding sexually transmitted diseases (STD) of $41(63.07 \%)$ dustmen of a country town in S. Paulo State, Brazil, are presented in order to provide support for the preparation of health education programmes on STD for this and similar populational groups. The data collected from interviews with these workers show that a considerable number of them have inadequate concepts about STD. These results demonstrate the lack of information and education on this subject, and the need to implement educational acitivities.

Keywords: Sexually transmitted diseases. Knowledge, attitudes, practice. Workers.

\section{Referências Bibliográficas}

1. ANTAL, G. Higiene sexual. Saúde Mundo, (nov.): 3-4, 1986.

2. BOLETIM EPIDEMIOLÓGICO AIDS. Brasília, Ministério da Saúde, 3(11) 1990.

3. BOLETIM EPIDEMIOLÓGICO DST. Brasília, Ministério da Saúde, 1(1) 1989.

4. JONES, M.O. O ambiente social. Saúde Mundo, (nov): 8-11, 1986

.5. MORIYA, T.M.; TAVARES, M.S.G.; OLIVEIRA, M.H.P; GIR, E. O que os jovens sabem sobre Doenças Sexualmente Transmitidas? Rev bras. Enf., Brasilia, 38: 300-5, 1985.

6. OLIVEIRA, M.H.P.; VIETTA, E.P.; MORIYA, T.M.; GIR, E. Reações emocionais dos portadores de DST no momento da confirmação do seu diagnóstico. Rev. bras. Enf - Brasília, 40:38-42, 1987.

7. ROBAZZI, M.L.C.C. Estudo das condiçōes de vida, trabalho e riscos ocupacionais a que estão sujeitos os coletores de lixo da cidade de Ribeirão Preto, Estado de São Paulo. Ribeirão Preto, 1984. [Dissertação de Mestrado - Escola de Enfermagem de Ribeirão Preto da USP]

Recebido para publicação em 31/10/1989 Reapresentado em 5/2/1991 Aprovado para publicação em 22/2/1991 